\title{
NUEVA PROPUESTA ESTRATIGRÁFICA: GEOLOGÍA DE LAS HOJAS MATAMBÚ Y TALOLINGA GUANACASTE, COSTA RICA
}

\author{
Kenneth Flores, Percy Denyer \& Teresita Aguilar \\ Escuela Centroamericana de Geología, \\ Apdo 2-14, 2060 Universidad de Costa Rica, San José \\ E-mail: kreyes@geología.ucr.ac.cr
}

\section{INTRODUCCIÓN}

Desde mediados de los años setentas (siglo XX), hubo un gran auge en el interés por las rocas de origen oceánico, produciendo gran cantidad de estudios en la península de Nicoya, específicamente en las rocas del Complejo de Nicoya. Sin embargo, la cobertura ha quedado relativamente descuidada. Además, casi todos los estudios que generaron propuestas de ordenamiento estratigráfico, después de Dengo (1962) y Rivier (1983), se localizaban en áreas costeras y el único trabajo regional reciente es el de Astorga (1987), cuyo aporte es fundamentalmente en la parte turbidítica del Cretácico terminal al Paleógeno. Por lo anterior se inició la revisión de la geología de áreas continentales y especialmente en las áreas que tuvieran menos información (Fig. 1), como parte del proyecto de investigación 113-90-071: Análisis geoestructural comparado de Costa Rica, que culminan con un informe detallado y una tesis de grado (Flores, 2003). En esta publicación se presentan algunos de los resultados más relevantes, principalmente en lo que respecta a las nuevas unidades propuestas, como se observa en la figura 2 y que son fundamentales para entender los mapas geológicos de las hojas Matambú y Talolinga (Serie: Colección de mapas geológicos 1 y 2, en este número).

Conceptualmente este trabajo se realizó desde lo particular a lo general, por lo que se partió de la geología local y detallada y, a partir de esto, se elaboraron las hipótesis y modelos estratigráficos, que se extrapolaron a otras áreas, para verificar su aplicabilidad y cartografiado. Se hizo la comparación y el reordenamiento litoestratigráfico y tectónico de la cobertura sedimentaria del Cretácico al Paleógeno, del área de estudio. En este trabajo se definen cimco unidades nuevas, que son: Fm. Berrugate, Fm. Nambí, Fm. Piedras Blancas, Miembro Quebrada Pavas y Miembro Zapotal. Además, se considera la redefinición de dos unidades (Flores, 2003).

La Formación Loma Chumico debe separarse del Complejo de Nicoya y ser usada únicamente para los sedimentos silíceos y bituminosos del Albiano Superior (Azema et al., 1979). La Fm. Sabana Grande debe usarse únicamente 
para referirse a los sedimentos silíceos y carbonatados de origen pélagico, hemipelágico y turbidítico, cuya edad corresponde con el CenomaniamoConiaciano. Esto excluye a los sedimentos turbidíticos y hemipelágicos del Coniaciano al Maastrichtiano Inferior basal, que ahora corresponderían con la Fm. Nambí y Fm. Piedras Blancas.

A continuación se describirán brevemente los cambios propuestos; en una futura publicación se detallarán estos aspectos.

\section{FORMACIÓN BERRUGATE}

Constituye la base sedimentaria de las secuencias aflorantes en el área oriental del golfo de Nicoya. Corresponde con sedimentos de composición epiclástica y volcaniclástica, que anteriormente se incluyeron en la Fm. Sabana Grande o en la Fm. Loma Chumico.

Descripción: Esta compuesta por 10 a 30 $\mathrm{m}$ de brechas basálticas, areniscas gruesas a medias de color gris a verde en estratos métricos a centimétricos e intercalaciones centimétricas de areniscas finas y lutitas silíceas con horizontes bituminosos. Microscópicamente son brechas y wackes líticas, lodolitas bituminosas y lodolitas silíceas. Seguida por 10 a $20 \mathrm{~m}$ de intercalaciones

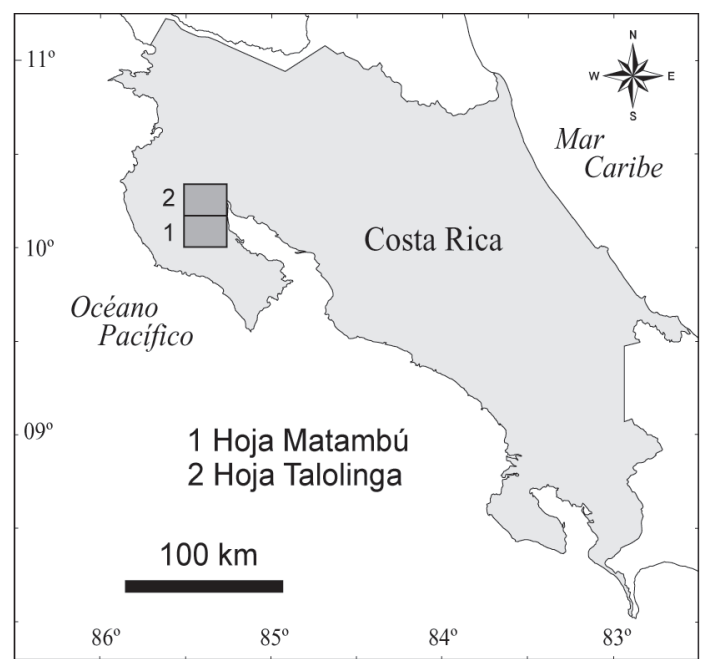

Fig. 1: Mapa de ubicación del área de estudio centimétricas a decamétricas de areniscas silíceas medias de color verde, areniscas silíceas finas, verdes y grises y lutitas silíceas verdes y cafés. Al meteorizar esta secuencia presenta un color blancuzco. Microscópicamente son lodolitas micríticas, lodolitas tobáceas e ignimbritas submarinas. La secuencia continúa con 10 a $20 \mathrm{~m}$ de intercalaciones centimétricas a decimétricas de areniscas calcáreas finas verdes con lutitas calcáreas gris verdosas, que en general presentan laminaciones paralela y cruzada. Microscópicamente son lodolitas micríticas y wackes arcósicas. La unidad termina con 10 a $20 \mathrm{~m}$ de lutitas calcáreas gris verdosas, lutitas calcáreagrises con laminaciones paralela y cruzada, y lutitas calcáreas parcialmente silicificadas (calizas silíceas blancas), que microscópicamente corresponden con lodolitas micríticas.

Estratotipo: Los afloramientos de la isla Berrugate, con hipoestratotipos en la isla Venado, isla Caballo, cercanías de Guastomatal de Nicoya y el flanco suroeste del cerro Barbudal.

Aspectos regionales: El máximo espesor observado es de $170 \mathrm{~m}$, al SE de los cerros San Pablo. La mayoría de los afloramientos se presentan al norte de la falla Morote, excepto los de isla Cedros. Su estratificación es decimétrica a centimétrica, en estratos tabulares y continuos, leve a medianamente plegada.

Relaciones estratigráficas: Sobreyace inconformemente a los basaltos del Complejo de Nicoya. En el área de Manzanillo de Puntarenas se encuentra sobreyacida discordantemente por la unidad informal Coyolito (Fernández, 1987) y en el cerro Barbudal está sobreyacida por la Fm. Barbudal.

Edad geológica: Se propone una edad del Cenomaniano Superior al Turoniano Inferior, basado en observaciones de las faunas de radiolarios, presencia de al menos un evento oceánico anóxico evidenciado en los sedimentos bituminosos, tales como los presentes en el área y el pozo Manzanillo (RECOPE), los cuales Astorga (1997) correlaciona con el OAE2. 
Aspectos específicos: La presencia de sedimentos volcaniclásticos de flujo y caída en esta unidad evidencian estructuras volcánicas subaéreas pre-campanianas. Calvo (1998) menciona que las rocas piroclásticas retrabajadas, que en este trabajo se asocian a la Fm. Berrugate, presentan una composición riodácitica, cuyo origen se asocia a productos volcánicos procedentes de erupciones plinianas subaéreas o marinas someras, lo que evidencia un vulcanismo explosivo de arco de islas.

Antecedentes: Esta unidad corresponde con los sedimentos silíceos de color verde que

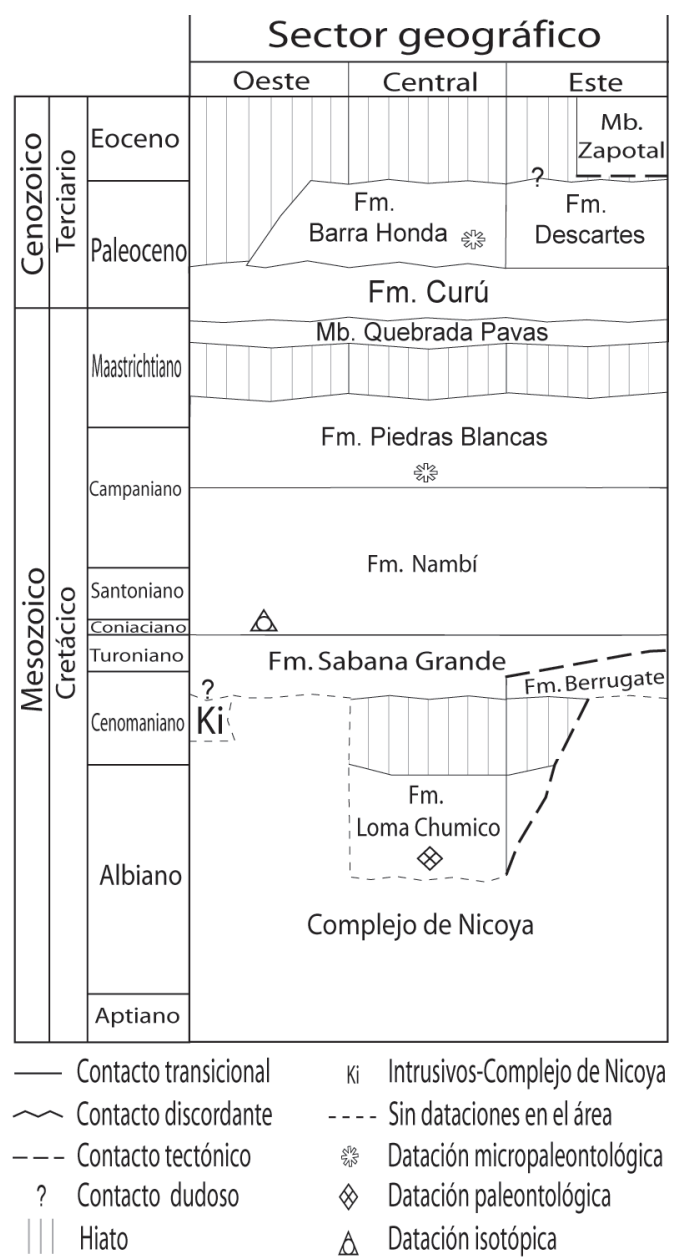

Fig. 2: Columna cronoestratigráfica autores anteriores asociaron a a las formaciones Loma Chumico y Sabana Grande (Dengo, 1962; Protti, 1981; Astorga, 1987; Calvo \& Boltz, 1994; Astorga, 1997 y Calvo, 1998). Seyfried \& Sprechmann (1985) son los primeros en mencionar la presencia de calizas silíceas y radiolaritas, tobas verdes (seladonitizadas) vítreas (ignimbritas submarinas) asociadas a un basamento basáltico en el cerro Barbudal. Fue llamada informalmente como unidad cerro Grande en la Campaña Geológica 1987.

\section{FORMACIÓN NAMBÍ}

Corresponde con sedimentos turbidíticos carbonatados que se intercalan entre los sedimentos pelágicos y hemipelágicos de las formaciones Sabana Grande y Piedras Blancas.

Descripción: Está compuesta por tres subunidades:

La subunidad inferior corresponde con un horizonte de $8 \mathrm{~m}$ de brechas basálticas con matriz arenosa, que pasan a areniscas masivas, medias a gruesas, con lentes brechosos en la quebrada Calosa. En Nambí y río Blanco corresponde con una secuencia de 20 a $50 \mathrm{~m}$ de areniscas finas gris oscuras, con intercalaciones de estratos, lentes y cuñas de lutitas y areniscas finas cafés y rojas, caracterizadas por laminaciones paralela y cruzada. Además, se caracterizan por presentar múltiples estructuras de carga y fragmentos de hasta $40 \mathrm{~cm}$ de largo de Inoceramus. Microscópicamente son wackes arcósicas.

La subunidad intermedia está constituida por 5 a $10 \mathrm{~m}$ de areniscas finas negras y cafés, lutitas cafés y cafés rojizas muy calcáreas y parcialmente silicificadas, que se caracterizan por un aspecto muy compacto. En algunas localidades se presentan fragmentos de Inoceramus. Microscópicamente son lodolitas micríticas con radiolarios y Globotruncanas. Seguida por 30 a 50 $\mathrm{m}$ de areniscas calcáreas medias grises, en estratos centimétricos o masivas. Se caracterizan por una alta compactación y a priori se confunden con basaltos. Algunas localidades se presentan 
altamente bioturbadas y con restos de madera. Microscópicamente son wackes líticas, wackes arcósicas y arenitas arcósicas.

La subunidad superior corresponde con 10 a $30 \mathrm{~m}$ de areniscas calcáreas medias a gruesas que pasan a calcarenitas medias y gruesas. Se encontraron fragmentos de rudistas, gasterópodos y bivalvos. Microscópicamente son wackes y packstones con macroforaminíferos globosos, posibles Orbitoides y Sulcoperculinas. Seguida por 30 a $60 \mathrm{~m}$ de intercalaciones centimétricas de lutitas cafés y areniscas medias grises, intercalaciones centimétricas de areniscas medias grises con laminaciones paralela y cruzada. En el río Blanco se encontraron fragmentos y ejemplares completos de gasterópodos no identificados. Microscópicamente corresponden con arenitas líticas y lodolitas micríticas con radiolarios y posibles Globotruncanas.

Estratotipo: Los afloramientos cercanos al poblado de Nambí y el cauce del río Blanco entre Tacanis y Guaria, con hipoestratotipo en río Blanco y Santa Ana de Nicoya.

Aspectos regionales: El máximo espesor calculado es de 130 m, en el área de Nambí. Los mejores afloramientos se presentan en el área de Nambí, Obispo, al NW de Santa Ana, río Blanco y al SE de isla Caballo. Su estratificación es decimétrica a centimétrica, en estratos tabulares y continuos, leve a intensamente plegada principalmente en las áreas cercanas a las fallas Morote y Espavelar.

Relaciones estratigráficas: Sobreyace inconformemente a los basaltos del Complejo de Nicoya. Su contacto inferior con la Fm. Sabana Grande es discordante, excepto en el área central, donde se evidencia un contacto transicional. Está sobreyacida concordantemente por la Fm. Piedras Blancas y discordantemente por la Fm. Curú. Los sedimentos café rojizos de la unidad intermedia se correlacionan con los depósitos sedimentarios producto de un Evento oceánico óxico (OOE), ocurrido durante Santoniano Superior al Campaniano Inferior (Hu et al., 2001).
Edad geológica: Varios ejemplares de fragmentos de Inoceramus procedentes de la subunidad inferior fueron datadas en la Universidad Lausanne (Suiza), mediante el método ${ }^{87} \mathrm{Sr} /{ }^{86} \mathrm{Sr}$, obteniéndose una edad Coniaciano Inferior. La parte superior presenta una microfauna típica del Campaniano Superior. Por lo que se propone una edad Coniaciano al Campaniano Superior.

Aspectos específicos: Esta unidad corresponde con una sedimentación turbidítica de origen basáltico, ocurrida durante el Coniaciano al Campaniano Superior. Los sedimentos de la parte inferior representan claramente las primeras rocas producto de la erosión del Complejo de Nicoya y la parte intermedia evidencia un hundimiento caracterizado por una sedimentación hemipelágica. La parte superior representa un nuevo evento turbidítico, caracterizado por mostrar la erosión una plataforma carbonatada del Campaniano Superior.

Antecedentes: Dengo (1962) la considera parte de la Fm. Rivas. Schmidt-Effing (1980) fue el primero en mencionar calizas turbidíticas silicificadas con macroforaminíferos en el área de Sabana Grande y Nambí y las asoció con la Fm. Sabana Grande. Según la estratigrafía propuesta por Astorga (1987) estas rocas se asociarían a los flujos turbulentos arenosos del Miembro Lutita calcárea Punta Blanca o como parte de las turbiditas de la Fm. Curú.

\section{FORMACIÓN PIEDRAS BLANCAS}

Dentro de esta unidad nueva se agrupan las rocas anteriormente reconocidas como caliza de la Fm. Rivas (Dengo, 1962), unidad Cuajiniquil (Protti, 1981), Fm. Caliza Pelágica Golfito (Baumgartner et al.,1984) y Miembro Lutita Calcárea Punta Blanca de la Fm. Sabana Grande (Astorga, 1987). Corresponde con sedimentos hemipelágicos ricos en globotruncanas del Cretácico Superior, que representa un horizonte correlacionable a nivel mundial producto de uno de los eventos oceánicos óxicos (OOEs), ocurrido en el mar de Tethys. 
Descripción: Está compuesta de la base al techo por:

- $\quad 1$ a $5 \mathrm{~m}$ de intercalaciones centimétricas a milimétricas de areniscas medias a finas rojas y calcilutitas rojas. Microscópicamente son wackes arcósicas con Globotruncanas.

- 6 a $20 \mathrm{~m}$ de calcilutitas rojas, rosadas y violáceas, que al alterarse presentan pátinas blancas. Microscópicamente son lodolitas micríticas con Globotruncana y barros de globotruncanas. En Copal y Santa Ana, este nivel presenta en su parte superior intercalaciones de estratos centimétricos de areniscas medias a finas grises. Al microscopio se observa que están separadas por contactos transicionales y erosivos. Microscópicamente corresponden con wackes arcósicas ricas en hornblenda verde.

- $\quad 8$ a 16 m de intercalaciones decimétricas a centimétricas de calcilutitas blancas grisáceas. Microscópicamente son lodolitas micríticas con Globotruncanas y barros de foraminíferos.

2 a $4 \mathrm{~m}$ de areniscas medias a gruesas, en estratos decimétricos a métricos, que sobreyacen a las calcilutitas blancas. Microscópicamente corresponden con arenitas arcósicas ricas en hornblenda verde.

Estratotipo: El corte de la carretera entre Uvita y Guaria, que se ubica en la parte alta del cerro Piedras Blancas $(227,05 N / 392,75 E)$. Con hipoestratotipos en el cauce del río Blanco entre Guaria y Tacanis.

Aspectos regionales: El espesor máximo observado es de $35 \mathrm{~m}$ y corresponde con el afloramiento del cerro Sombrero. Se conocen rocas similares en casi toda la península de Nicoya, destacándose las localidades al norte de la península de Santa Elena y Puerto Carrillo. Su estratificación es centimétrica a decimétrica, en estratos tabulares y continuos, leve a medianamente plegadas, principalmente en áreas cercanas a grandes estructuras, tal como la falla Uvita.
Relaciones Estratigráficas: Sobreyace inconformemente a las rocas asociadas al Complejo de Nicoya. Discordantemente, en contacto erosivo, a los sedimentos de la Fm. Sabana Grande. El contacto con la Fm. Nambí es transicional. Está sobreyacida discordantemente, en contacto erosivo, por el Miembro Quebrada Pavas de la Fm. Curú.

Edad geológica: Dataciones micropaleontológicas realizadas en la Universidad de Lausanne indican una fauna de foraminíferos planctónicos de la zona Gansseri de la zonación de globotruncanas de Robaszynski et al. (1984). Esta zona es asignada al Campaniano Superior terminal hasta el Maastrichtiano Inferior basal (Mora-Baumgartner, com. escrita, 2003).

Aspectos específicos: En la localidad tipo Claudia Mora-Baumgartner (com. esc., 2003) determinó: Globotruncana insignis, Globotruncanita pettersi, Globotruncanita stuartiformis, Globotruncana linneiana, Ganserina gansseri, Heterohelix cf. navarroensis, Heterohelix cf. reussi, Globotruncanita stuarti, Rosita sp., Rosita fornicata, Globotrunacanita subspinosa, Globotruncana bulloides y Globotruncana falsostuarti.n. Madrigal (com. pers., 2002) reporta el hallazgo de un amonite desenrollado en el cerro Sombrero, Copal. Las rocas de esta unidad evidencian una sedimentación carbonatada hemipelágica que traducen una subsidencia regional de la cuenca. Constituyen un horizonte guía correlacionable a nivel mundial, pues se asocia al segundo y más importante OOEs representado en Costa Rica.

Antecedentes: Dengo (1962) menciona por primera vez la presencia de calizas silíceas gris-rosadas, intercaladas con lutitas silíceas rosadas y capas delgadas de ftanita cerca de Montezuma y las asocia al Complejo de Nicoya. Además, Dengo (1962) describe la parte inferior de la unidad superior de la Fm. Rivas, como compuesta por un miembro de calizas lutíticas grises a pardas. Protti (1981) las cartografió como unidad Cuajiniquil. Baumgartner et al. 
(1984) incluye estas rocas dentro de la Fm. Caliza Pelágica Golfito. Astorga (1987) las agrupa en la Fm. Sabana Grande, dándole el rango de Miembro Lutita Calcárea Punta Blanca.

\section{MIEMBRO QUEBRADA PAVAS (Fm. Curú)}

Esta unidad es la base de la Fm. Curú, se caracteriza por evidenciar un evento de alta erosión durante el Maastrichtiano Superior.

Descripción Es una secuencia de 20 a 50 $\mathrm{m}$, compuesta por estratos métricos a centimétricos de areniscas medias a gruesas grises, con lentes de conglomerados con clastos redondea$\operatorname{dos}(\varnothing=2-10 \mathrm{~cm})$ de basaltos, pedernales, radiolaritas, lutitas silíceas y clastos angulares $(10 \mathrm{x}$ $30 \mathrm{~cm}$ ) de calcilutitas rosadas y blancas. Esta unidad se caracteriza por presentar laminación paralela planar continua y megaestratificación cruzada. Microscópicamente corresponden con arenitas líticas, wackes líticas y arenita arcósica.

Estratotipo: El curso bajo de la quebrada Pavas (224,85N/392,2E), con hipoestratotipos en la quebrada Carreta cerca de Sabana Grande y la quebrada Grande en Tacanis.

Aspectos regionales: El espesor máximo observado en la localidad tipo, es de $50 \mathrm{~m}$. Entre los mejores afloramientos de esta unidad, están quebrada Pavas, quebrada Grande, cerro Coyolar y flanco norte del cerro Piedras Blancas en la hoja Matambú. Quebrada Carreta, quebrada Arena, Lomas de Chirco y loma del Tanque AyA de Nambí en la hoja Talolinga. Su estratificación es métrica a decimétrica, en estratos tabulares y continuos, aunque los conglomerados son lenticulares y discontinuos.

Relaciones Estratigráficas: Sobreyace dicordantemente a los sedimentos de la Fm. Piedras Blancas. El contacto es erosivo. Está sobreyacida concordantemente por intercalaciones centimétricas de lutitas cafés calcáreas de la Fm. Curú.
Edad geológica: Maastrichtiano Superior basal, por correlación, ya que sobreyace a la Fm. Piedras Blancas.

Aspectos específicos: Esta unidad evidencia un evento de alta erosión en la cuenca, el cual posiblemente fue producto de un levantamiento general de la cuenca, lo que produjo una alta erosión en un tiempo muy corto.

\section{MIEMBRO ZAPOTAL (Fm. Descartes)}

Dentro de esta unidad se agrupan los sedimentos de origen turbidítico, antes asociados a la Fm. Brito (Dengo, 1962 y Rivier, 1983), así como el Miembro Cerro la Peña de la Fm. Brito (Denyer et al., 1987).

Descripción: Rivier (1983) la describe en el área de Colorado como alternancias de calcilutitas, calcarenitas, tobas finas y tobas conglomerádicas, en la parte superior. Denyer et al. (1987) mencionan la existencia de rocas similares al Miembro Zapotal en el área de la Campaña Geológica de 1987, las cuales designan como Miembro Cerro Peña, compuesto por $30 \mathrm{~m}$ de lodos calcáreos (a veces calizas silíceas), calcarenitas finas, areniscas medias a gruesas calcáreas y tobas grises. Con laminaciones plana paralela, ondulada y cruzada de bajo ángulo; más $40 \mathrm{~m}$ de areniscas gruesas calcáreas, areniscas guijarrosas y brechas finas, de color blancuzco a verde. La secuencia presenta estratificación decimétrica a métrica. Basado en el trabajo Campo II (1994) y en observaciones de campo, el Miembro Zapotal, en la isla de Chira, está compuesto por $450 \mathrm{~m}$ de intercalaciones centimétricas de areniscas calcáreas finas y gruesas, con laminación paralela y estructuras de carga; 250 $\mathrm{m}$ de intercalaciones centimétricas de areniscas calcáreas medias y finas con lutitas, de color gris que al meteorizarse son de color rojo; 350 $\mathrm{m}$ de intercalaciones centimétricas de lutitas y areniscas finas silíceas de color crema, que meterorizan de color rojizo y, finalmente, $1000 \mathrm{~m}$ 
de intercalaciones centimétricas de lutitas y areniscas silíceas finas, areniscas calcáreas medias y finas y lutitas calcáreas. Microscópicamente corresponden con lodolitas tobáceas, barros de foraminíferos y wackes líticas con detrito volcánico.

Estratotipo: Corresponde con la secuencia aflorante en los cerros Zapotal, en el área de Colorado; como hipoestratotipo se proponen los afloramientos de la isla de Chira.

Aspectos regionales: El espesor máximo calculado es mayor que $2000 \mathrm{~m}$. Esta unidad aflora en el sector norte y oriental del golfo de Nicoya. Su estratificación es centimétrica a decimétrica, en estratos tabulares y continuos, leve a moderadamente plegados, producto de deformación sinsedimentaria.

Relaciones estratigráficas: Sobreyace concordantemente al Miembro Cerco de Piedra y discordantemente a la Fm. Descartes. Según Denyer (1977) este contacto es transicional. En el sector de San Buenaventura y el sur del río Tempisque está sobreyacida tectónicamente por la Fm. Barra Honda. Denyer et al. (1987) indican que en el área de Arizona (Abangares), está sobreyacida discordantemente por el Miembro Cerro Lagarto de la Fm. Punta Carballo y el Grupo Aguacate.

Edad geológica: Rivier (1983) le asigna una edad entre el Paleoceno Superior y el Eoceno Inferior.

Aspectos específicos: Rivier (1983) reporta la siguiente microfauna: Globorotalia formosa formosa Bolli, Globorotaria aragonensis Nuttal y Globorotalia formosa gracilis Bolli. En varios informes de la Campaña Geológica 1977 se mencionan Numulites.

Antecedentes: Dengo (1962) incluye esta unidad dentro de Fm. Brito. Fue llamada informalmente como unidad Zapotal durante la Campaña Geológica de 1977 y unidad Cerro Peña durante la Campaña Geológica de 1987. Fue designado como un miembro de la Fm. Descartes por Astorga (1987).

\section{REFERENCIAS}

ALPIZAR, R., ARIAS, M., BRENES, W., MORA, M., SALAZAR, J., VARGAS, I. \& DENYER, P., 1994: Estudio geológico integral de la isla Chira, península de Nicoya, Costa Rica. - 43 págs. Univ. Costa Rica, San José [Inf. Campo II].

ASTORGA, A., 1987: El Cretácico Superior y el paleógeno de la vertiente pacífica de Nicaragua meridional y Costa Rica septentrional: Origen, evolución y dinámica de las cuencas profundas relacionadas al margen convergente de Centroamérica. - 115 págs. Univ. Costa Rica [Tesis Lic.]

ASTORGA, A., 1997: El puente-istmo de América Central y la evolución de la Placa Caribe (con énfasis en el Mesozoico). - Profil, 12:1-201.

AZEMA, J., TOURNON, J. \& SORMAY, J., 1979: Presencia de amonites del Albiano Superior en las formaciones del Complejo de Nicoya. El yacimiento de Loma Chumico, provincia de Guanacaste, Costa Rica. - Inf. Sem. IGN, 1978 (2): 71-76.

BAUMGARTNER, P. O., MORA, C.R., BUTTERLIN, J., SIGAL, J., GLACON, G., AZEMA, J. \& BOURGOIS, J., 1984: Sedimentología y Paleogeografía del Cretácico y Cenozoico del litoral pacífico de Costa Rica. - Rev. Geol. Amér. Central, 1: 57-136.

CALVO, C. \& BOLZ, A., 1994: Der älteste kalkalkaline Inselbogen-Vulcanismus in Costa Rica. Pyroklastite der Formation Loma Chúmico (Alb bis Campan). - Profil 7: 235-264.

CALVO, C., 1998: Kretazische Subduktionsprozesse in Südzentralamerika. - Profil 15: 1-161. 
DENGO, G., 1962: Estudio geológico de la región de Guanacaste, Costa Rica. - 112 págs. IGN, San José.

DENYER, P., 1977: Geología del cerro Zapote y alrededores, Colorado de Abangares, Guanacaste, Costa Rica. - 10 págs. Univ. de Costa Rica [Inf. Campaña Geológica].

DENYER, P., MONTERO, W., SOTO, G., QUEZADA, A., LEANDRO, L., PÉREZ, C. \& RODRÍGUEZ, D., 1987: Geología y tectónica de la margen oriental del golfo de Nicoya, Costa Rica. - Ciencia y Tecnol. 11(2): 17-31.

FERNÁNDEZ, M., 1987: Geología del área entre Abangaritos y Manzanillo. Provincia de Puntarenas. - 69 págs. Univ. Costa Rica, San José [Inf. Campaña Geológica].

FLORES, K., 2003: Propuesta tectonoestratigráfica de la región septentrional del golfo de Nicoya, Costa Rica. - 176 págs. Univ. Costa Rica, San José [Tesis Lic.]

HU, X., WANG, C., LI, X. \& JANSA, L., 2001: Late oceanic event in Tibetan Himalayas. - GSA. http://gsa.confex.com/gsa/
2001ESP/final program/abstract 6544.htm [consulta 7 jun. 2002]

PROTTI, R., 1981: Geología y geofísica con fines hidrogeológicos en la planicie costera Jicaral-Santa Rita, península de Nicoya, Costa Rica. - 47 págs. Univ. Costa Rica, San José [Tesis Lic.].

RIVIER, F., 1983: Síntesis geológica y mapa geológico del área de bajo Tempisque, Guanacaste, Costa Rica. - Inf. Sem. IGN, 1983(1): 7-30.

ROBAZYNSKI, F., CARON, M., GONZALES DONOSO, J.M. \& WONDERS, A.A., 1984: Atlas of Late Cretaceous Globotruncanids. - Revue Micropaléont. 26: 145-305.

SCHMIDT-EFFING, R., 1980: Rasgos fundamentales de la historia del Complejo de Nicoya (América Central meridional). Brenesia, 18: 231-252.

SEYFRIED, H. \& SPRECHMANN, P., 1985: Acerca de la formación del puente-istmo Centroamericano Meridional, con énfasis en el desarrollo acaecido desde Campanénse al Eoceno. - Rev. Geol. Amér. Central, 2:63-87. 